\title{
Analyzing Small Industrial and Commercial User Demand for Electricity
}

\author{
Keighton R. Allen1, Thomas M. Fullerton Jr. ${ }^{2}$ \\ ${ }^{1}$ Corporate Planning Department, El Paso Electric Company, El Paso, USA \\ ${ }^{2}$ Department of Economics \& Finance, University of Texas at El Paso, USA \\ Email: tomf@utep.edu
}

How to cite this paper: Allen, K.R. and Fullerton Jr., T.M. (2018) Analyzing Small Industrial and Commercial User Demand for Electricity. Theoretical Economics Letters, 8, 3109-3115.

https://doi.org/10.4236/tel.2018.814193

Received: September 15, 2018

Accepted: October 22, 2018

Published: October 25, 2018

Copyright $\odot 2018$ by authors and Scientific Research Publishing Inc. This work is licensed under the Creative Commons Attribution International License (CC BY 4.0).

http://creativecommons.org/licenses/by/4.0/

\section{(c) (i) Open Access}

\begin{abstract}
This study employs duality theory to develop a theoretical model for small commercial and industrial (CIS) electricity usage. The CIS production function is posited such that output is a function of three variable inputs (electricity, natural gas, and labor) and one fixed input (capital). A profit function dual to this production function is specified using a normalized quadratic functional form. CIS profits are functionally dependent upon output price, an electricity input price, and natural gas and labor input prices for a fixed quantity of capital. The derived input-demand equation results from differentiating the profit function with respect to the price of electricity. The input-demand equation for electricity is dependent upon the own-price of electricity, the CIS output price, and input cross-prices. The model may be of use to utilities and regulators for the analysis of CIS electricity usage.
\end{abstract}

\section{Keywords}

Duality Theory, Derived Demand, Electricity, Small Industrial and Commercial

\section{Introduction}

Because of the importance of electricity in modern economies, substantial research is devoted to the analysis of electricity usage. Historically, residential consumption patterns have been extensively researched with comparatively less attention devoted to small industrial and commercial (CIS) demand. CIS usage, defined here as usage that does not exceed 600 kilowatts in any two consecutive months, represents a large portion of total electricity consumption and deserves more scrutiny [1] [2]. By extension, relatively few studies develop theoretical frameworks for analyzing CIS electricity usage. 
It is helpful for regional utilities and regulatory agencies to understand how changes in economic conditions affect CIS electricity consumption. Regional economic growth frequently mandates additional generation capacity investments [3] [4]. There is no set manner in which regional CIS usage patterns behave, so that process likely to exhibit substantial heterogeneity across different public utilities [5].

This study proposes a theoretical approach for the analysis of CIS electricity consumption. Duality theory and derived demand are employed for specification of the input-demand equation for electricity. Sectorial output supply functions also result within this framework, but the focus of this effort is CIS usage of electricity as an input into production. Derived demand refers to demand that results for one good as a result of demand for another product. As shown below, partial differentiation of the profit function with respect to the price of electricity yields the input demand equation.

The rest of the study is organized as follows. Section 2 provides a review of related energy and microeconomic studies. Section 3 summarizes the model that is developed. Section 4 concludes with suggestions for future research.

\section{Literature Review}

Much of the prior research using duality theory and derived input demand has been for use in agricultural economics. In this effort, a normalized quadratic functional form for the underlying profit function dual to a production function is used to describe CIS usage for electricity as derived demand [6] [7] [8] [9] [10]. Duality theory posits the existence of a profit function dual of a production function in a manner that conforms with firm profit-maximizing behavior [6]. The dual approach assumes profit-maximizing firms are price-takers and operate in a perfectly competitive market [11] [12]. For small industrial and commercial firms, these are reasonable assumptions.

The quadratic functional form is widely used in empirical research of the dual approach [11] [12] [13]. Thompson and Langworthy [14] illustrate that identical results for the primal and dual approach are obtained only if the flexible functional form is self-dual, such as the quadratic functional form. Lusk, Featherstone, Marsh, and Abdulkadri [15] empirically examine the dual relationship between the parameters of the normalized quadratic production function, the unrestricted profit function, and the restricted profit function. Because the estimated quadratic functional form matches the data-generating process, the elasticity estimates from the production, unrestricted profit, and restricted profit functions produce similar results [15]. The use of quadratic flexible functional form also allows for the estimation of own-price, cross-price, and output-price elasticities subject to minimal a priori restrictions [6].

A normalized quadratic restricted profit function is used to derive a model of CIS electricity demand using one output, three variable inputs, and one fixed input. A profit function, as opposed to a cost function, is utilized because it is 
simpler to estimate and no endogenous variables are needed as explanatory variables [16]. Input prices are normalized prior to specification and estimation to impose homogeneity [11] [15].

This effort attempts to model CIS electricity usage within a formal analytical context. The model developed in the next section is based upon duality theory [6] [7]. Electricity usage by the CIS rate class is ultimately specified as a derived input demand function [11].

\section{Theoretical Framework}

The first step in developing a demand function using duality theory is to specify a production function. Electricity demand is derived demand, meaning it is used as an input in the commercial and industrial sector as a factor of production in the output of final goods and services [11] [17] [18]. As the demand for those goods and services increases, CIS electricity consumption should increase in response [6] [7] [17]. A general production function using $X_{i}$ variable inputs and a $Z_{K}$ fixed input is illustrated in Equation (1). The fixed input may vary in the long-run, but not in the short-run production period [11] [13]. Output $(Q)$ is expressed as a function of three variable input quantities, $X_{i}$ : electricity $\left(X_{E}\right)$, natural gas $\left(X_{G}\right)$, and labor $\left(X_{L}\right)$, and one fixed input quantity, capital $\left(Z_{K}\right)$ in Equation (2). The production function is assumed to be concave, non-negative, continuous, smooth, and monotone [11].

$$
\begin{gathered}
Q=f\left(X_{i} ; Z_{K}\right) \\
Q=f\left(X_{E}, X_{G}, X_{L} ; Z_{K}\right)
\end{gathered}
$$

CIS demand for electricity as an input is derived from CIS output using a restricted profit function [6] [7]. The profit function is hypothesized to be dual to the production function. CIS firms are assumed to be price-takers in the input and output markets and operate in a competitive market, where only normal profits result in the long run [11].

CIS firms maximize profit by choosing the quantity of output supplied, $Q$, and the quantities of the three variable inputs, $\left(X_{i}=X_{E}, X_{G}, X_{L}\right)$. Output price and the variable input prices $\left(P_{i}=P_{Q}, P_{E}, P_{G}, P_{L}\right)$ are exogenously determined [9] [11]. In addition to exogenous input and output prices, CIS firms are restricted in the use of capital input $\left(Z_{K}\right)$ [9]. Derived demand for electricity as an input is a function of output price, its own price, and the prices of natural gas and labor, given a fixed quantity of capital, as shown in Equation (3) [19]. Equation (4) is the profit maximization decision.

$$
\begin{gathered}
\Pi=f\left(P_{i} ; Z_{K}\right) \\
\Pi\left(P_{Q}, P_{E}, P_{G}, P_{L} ; Z_{K}\right)=\max _{X_{i}, Q}\left\{P_{Q} * Q-P_{i}^{\mathrm{T}} X_{i} ;\left(Q, X_{i} ; Z_{K}\right) \epsilon T\right\}
\end{gathered}
$$

The normalized quadratic functional form is the most appropriate means for the specifying the restricted profit function as shown in Equation (5) [7] [8] [20]. The normalized quadratic functional form satisfies most of the assumptions of 
demand theory. A comprehensive description of the restricted profit function is offered by Lau [21]. For the normalized quadratic restricted profit function to be theoretically valid, Equation (6) must be non-negative, convex, continuous, and homogeneous of degree one in output and input prices, and concave and continuous in the fixed input [11] [22] [23]. Furthermore, regularity conditions and symmetry conditions for $\beta_{i j}=\beta_{j i}$ are imposed on the profit function [15]. Output and input prices, $P_{i}$, are normalized before specification and estimation [11] [15] [20].

$$
\begin{aligned}
\Pi\left(P_{i} ; Z_{K}\right)=\sum_{i}^{4} \beta_{i} P_{i} & +\beta_{K} Z_{K}+\frac{1}{2} \sum_{i}^{4} \sum_{j}^{4} \beta_{i j} P_{i} P_{j}+\frac{1}{2} \beta_{K K} Z_{K}^{2}+\sum_{i}^{4} \beta_{i K} P_{i} Z_{K} \\
\Pi\left(P_{Q}, P_{E}, P_{G}, P_{L} ; Z_{K}\right)= & \beta_{Q} P_{Q}+\beta_{E} P_{E}+\beta_{G} P_{G}+\beta_{L} P_{L}+\beta_{K} Z_{K}+\frac{1}{2}\left[\beta_{Q Q} P_{Q}^{2}\right. \\
& +\beta_{E E} P_{E}^{2}+\beta_{G G} P_{G}^{2}+\beta_{L L} P_{L}^{2}+\beta_{Q E} P_{Q} P_{E}+\beta_{Q G} P_{Q} P_{G} \\
& \left.+\beta_{Q L} P_{Q} P_{L}+\beta_{E G} P_{E} P_{G}+\beta_{E L} P_{E} P_{L}+\beta_{G L} P_{G} P_{L}+\beta_{K K} Z_{K}^{2}\right] \\
& +\beta_{Q K} P_{Q} Z_{K}+\beta_{E K} P_{E} Z_{K}+\beta_{G K} P_{G} Z_{K}+\beta_{L K} P_{L} Z_{K}
\end{aligned}
$$

Based on Hotelling's lemma, the profit function is differentiable on output and input prices. Differentiation of Equation (6) with respect to $P_{E}$ using Hotelling's lemma yields the negative input-demand function for electricity or $\frac{\partial \Pi\left(P_{i} ; Z_{K}\right)}{\partial P_{E}}=-X_{E}^{*}$. Because the focus of this paper is CIS electricity demand, only the input-demand function for electricity is explicitly derived in Equation (7). The input-demand function is homogeneous of degree zero in prices, and symmetry constraints result for the coefficients of Equation (7) such that $\beta_{i j}=\beta_{j i} \quad[11]$.

$$
-\frac{\partial \Pi\left(P_{i} ; Z_{K}\right)}{\partial P_{E}}=X_{E}^{*}=\beta_{E}+\beta_{E E} P_{E}+\beta_{Q E} P_{Q}+\beta_{E G} P_{G}+\beta_{E L} P_{L}+\beta_{E K} Z_{K}
$$

Finally, the own-price, cross-price, and output-price elasticities of electricity demand are extracted from the derived input-demand function. Reciprocity constraints, also known as symmetry conditions, are imposed on the derivatives of the input-demand function, so that $\frac{\partial X_{i}^{*}}{\partial P_{j}}=\frac{\partial X_{j}^{*}}{\partial P_{i}}$. One advantage of deriving demand equations from flexible functional forms using duality theory is that the elasticities of demand are subject only to those restrictions implied by economic theory [7]. The own-price elasticity of electricity demand is defined in Equation (8). If $P_{j}$ is the price of the other inputs, the cross-price elasticities of electricity demand with respect to the price of natural gas and the wage rate are defined in Equation (9) for the sample means. Equation (10) defines the output-price elasticity of electricity demand with respect to $P_{Q}$ at the sample means.

$$
\varepsilon_{X_{E}, P_{E}}=\frac{\partial X_{E}^{*}}{\partial P_{E}} * \frac{P_{E}}{X_{E}^{*}}=-\left(\beta_{E E}\right) \frac{\overline{P_{E}}}{\overline{X_{E}}}
$$




$$
\begin{gathered}
\varepsilon_{X_{E}, P_{j}}=\frac{\partial X_{E}^{*}}{\partial P_{j}} * \frac{P_{j}}{X_{E}^{*}}=\left(\beta_{E j}\right) \frac{\overline{P_{j}}}{\overline{X_{E}}} \\
\varepsilon_{X_{E}, P_{Q}}=\frac{\partial X_{E}^{*}}{\partial P_{Q}} * \frac{P_{Q}}{X_{E}^{*}}=\left(\beta_{Q E}\right) \frac{\overline{P_{Q}}}{\overline{X_{E}}}
\end{gathered}
$$

The own-price elasticity coefficient is hypothesized to be negative, meaning an increase in the price of electricity will reduce CIS electricity consumption. The signs of the cross-price elasticity estimates are ambiguous, depending on whether electricity and natural gas and labor are substitutes or complements. If electricity and the alternate inputs are substitutes, an increase in the prices of those inputs will increase the demand for electricity, resulting in positive elasticity coefficients. If electricity and the inputs are complements, an increase in the prices of those inputs will decrease the demand for electricity, resulting in negative elasticity coefficients.

The analytical framework developed herein provides a logical starting point for empirical analyses of CIS electricity usage. Doing so will require collecting a combination of electric utility data and broader economic measures. Data assembly will require some effort, but should prove manageable for many regions and/or nations. Whether econometric evidence is eventually compiled that confirms the usefulness of the approach, of course, remains to be seen.

\section{Conclusions}

Small commercial and industrial (CIS) electricity represents a large percentage of total loads for many electric utilities. In spite of that, CIS demand has historically received far less attention than residential usage. A natural step toward addressing that gap in the energy economics literature is development of a formal modelling construct. This study attempts to do that.

The duality theory framework employed here specifies a CIS production function where output is expressed as a function of three variable input quantities (electricity, natural gas, and labor) and one fixed input quantity (capital). The dual to this production function is a profit function. A normalized quadratic functional form characterizes the restricted profit function. The profit function is a function of an output price, an electricity price, and the prices of natural gas and labor, given a fixed quantity of capital. Using Hotelling's lemma, the input-demand equation is derived by differentiating the profit function with respect to the price of electricity. From the input-demand equation for electricity, the own-price, output-price, and cross-price price elasticities are derived.

Estimation of the derived input-demand equation above and should yield reliable, comparable results for regional electric utility empirical research. One advantage of duality theory is the capability to derive an input-demand equation consistent with profit-maximizing behavior. Although endogeneity may come into play, a similar approach based on cost-minimizing behavior can likely be developed for cases involving publically owned utilities. The dual approach in- 
cludes all the elements of prior studies that use simpler models [17]. However, the dual approach also includes inputs such as labor and capital in the input-demand equation, previously ignored by many studies. A less-robust approach might exclude these and other important, explanatory variables. The approach employed in this effort is one that seems to merit testing using data from electric utilities and metropolitan, regional, or national economies.

\section{Acknowledgements}

Financial support for this research was provided by El Paso Water, City of El Paso Office of Management \& Budget, National Science Foundation Grant DRL-1740695, the UTEP Center for the Study of Western Hemispheric Trade, and the Hunt Institute for Global Competitiveness at UTEP. Helpful comments were provided by Jim Holcomb, Richard Jarvis, and an anonymous referee. Econometric research assistance was provided by Omar Solis and Esmeralda Muñiz.

\section{Conflicts of Interest}

The authors declare no conflicts of interest regarding the publication of this paper.

\section{References}

[1] Roback, J. (1982) Wages, Rent, and the Quality of Life. Journal of Political Econo$m y$, 90, 1257-1278. https://doi.org/10.1086/261120

[2] Voith, R. (1991) Capitalization of Local and Regional Attributes into Wage and Rents: Differences Across Residential, Commercial and Mixed-Use Communities. Journal of Regional Science, 31, 127-145. https://doi.org/10.1111/j.1467-9787.1991.tb00138.x

[3] Fullerton, T.M., Jr., Juarez, D.A. and Walke, A.G. (2012) Residential Electricity Consumption in Seattle. Energy Economics, 34, 1693-1699.

https://doi.org/10.1016/j.eneco.2012.02.004

[4] Bildirici, M.E. (2013) The Analysis of Relationship Between Economic Growth an Electricity Consumption in Africa by ARDL Method. Energy Economics Letters, 1, 1-14. http://www.aessweb.com/pdf-files/EEl\%201(1),\%201-14..pdf

[5] Fullerton Jr., T.M., Macias, D.R. and Walke, A.G. (2016) Residential Electricity Demand in El Paso: 1977-2014. Journal of Regional Analysis \& Policy, 46, 154-167. http://www.jrap-journal.org/pastvolumes/2010/v46/jrap_v46_n2_a4_fullerton_etal. pdf

[6] Halvorsen, R. (1977) Energy Substitution in U.S. Manufacturing. Review of Economics and Statistics, 59, 381-388. https://doi.org/10.2307/1928702

[7] Halvorsen, R. (1978) Econometric Models of U.S. Energy Demand. Lexington Books, Lexington.

[8] Diewert, W.E. and Ostensoe, L. (1988) Flexible Functional Forms for Profit Functions and Global Curvature Conditions. In: Barnett, W.A., Berndt, E.R. and White, H., Eds., Dynamic Econometric Modeling. Proceedings of the Third International Symposium in Economic Theory and Econometrics, Cambridge University Press, Cambridge, 43-51. https://doi.org/10.1017/CBO9780511664342.004 
[9] Dupont, D.P. (1991) Testing for Input Substitution in a Regulated Fishery. American Journal of Agricultural Economics, 73, 155-164. https://doi.org/10.2307/1242891

[10] Lusk, J., Featherstone, A. and Abdulkadri, A. (1999) An Examination of the Empirical Properties of Duality between the Restricted Profit, Unrestricted Profit, and Production Function. American Agricultural Economics Association 1999 Annual Meeting, Nashville, 8-11 August 1999. http://ageconsearch.umn.edu/record/21718/files/sp99lu02.pdf

[11] Fullerton Jr., T.M. and Huffman, W.E. (1995) Supply Functions for Fresh Market Vegetables. Studies in Regional Science, 25, 1-17. https://doi.org/10.2457/srs.25.2_1

[12] Yamaura, K. and Featherstone, A.M. (2016) Estimating the Effect of Monopsony Power on Elasticity Estimates. Applied Economics, 48, 179-189. https://doi.org/10.1080/00036846.2015.1076148

[13] Huffman, W.E. and Evenson, R. (1989) Supply and Demand Functions for Multiproduct U.S. Cash Grain Farms: Biases Caused by Research and Other Policies. American Journal of Agricultural Economics, 71, 761-773. https://doi.org/10.2307/1242032

[14] Thompson, G. and Langworthy, M. (1989) Profit Function Approximations and Duality Applications to Agriculture. American Journal of Agricultural Economics, 71, 791-798. https://doi.org/10.2307/1242035

[15] Lusk, J., Featherstone, A., Marsh, T. and Abdulkadri, A. (2002) Empirical Properties of Duality Theory. Australian Journal of Agricultural and Resource Economics, 46, 45-68. https://doi.org/10.1111/1467-8489.00166

[16] Lopez, R. (1984) Estimating Substitution and Expansion Effects Using a Profit Function Framework. American Journal of Agricultural Economics, 66, 358-367. https://doi.org/10.2307/1240803

[17] Watson, M.W., Pastuszek, L.M. and Cody, E. (1987) Forecasting Commercial Electricity Sales. Journal of Forecasting, 6, 117-136. https://doi.org/10.1002/for.3980060206

[18] Jamil, L. and Ahmad, E. (2011) Income and Price Elasticities of Electricity Demand: Aggregate and Sector-Wise Analyses. Energy Policy, 39, 5519-5527. https://doi.org/10.1016/j.enpol.2011.05.010

[19] Berndt, E.R. and Wood, D.O. (1975) Technology, Prices and the Derived Demand for Energy. Review of Economics and Statistics, 57, 259-268. https://doi.org/10.2307/1923910

[20] Dupont, D.P. and Gordon, D.V. (2007) Shadow Prices for Fishing Quotas: Fishing with Econometrics. In: Bjorndal, T., Gordon, D., Arnason, R. and Sumaila, U., Eds., Advances in Fisheries Economics. Festschrift in Honour of Professor Gordon $R$. Munro. Blackwell Publishing Ltd., Oxford, 87-108. https://doi.org/10.1002/9780470751589.ch6

[21] Lau, L.J. (1976) A Characterization of the Normalized Restricted Profit Function. Journal of Economic Theory, 12, 131-163. https://doi.org/10.1016/0022-0531(76)90030-2

[22] Maligaya, A. and White, F. (1989) Agricultural Output Supply and Input Demand Relationships with Endogenous Land Rents. Southern Journal of Agricultural Economics, 21, 13-20. https://doi.org/10.1017/S0081305200001138

[23] Boonsaeng, T. and Wohlgenant, M.K. (2006) The Demand for Livestock by the U.S. Meat Processing Industry. American Agricultural Economics Association Annual Meeting, Long Beach, 23-26 July 2006.

https://ageconsearch.umn.edu/bitstream/21120/1/sp06bo07.pdf 